\title{
Surface Modification of Parts Material Shape Memory TiNiCo with a View to Providing a Functional and Mechanical Property as a Factor in Resource
}

\author{
Peter Olegovich Rusinov' ${ }^{1}$ Zhesfina Michailovna Blednova ${ }^{2}$ \\ ${ }^{1}$ Faculty of Engineering \& Services, Kuban State Technological University, Krasnodar, Russia \\ ${ }^{2}$ Department of Dynamics and Strength of Machines, Kuban State Technological University, Krasnodar, Russia \\ Email: ruspiter5@mail.ru
}

Received 21 August 2014; revised 18 September 2014; accepted 30 September 2014

Copyright $@ 2014$ by authors and Scientific Research Publishing Inc.

This work is licensed under the Creative Commons Attribution International License (CC BY).

http://creativecommons.org/licenses/by/4.0/

(c) $\underset{\mathrm{EY}}{\mathrm{EY}}$ Open Access

\begin{abstract}
The paper presents a complex method of forming the surface-modified layers of materials with shape memory effect, including high-speed flame spraying of powders based on TiNiCo; subsequent thermal and thermomechanical treatment allows the formation of surface layers of nanosized state that have a high level of functional, mechanical and performance properties; it is shown that the complex processing with a layer of TiNiCo allows a reduction of the porosity of the coatings and increases the strength of the coating's adhesion to the substrate. It is found that, after treatment with high-speed flame spraying powder shape memory TiNiCo, steel has an increase in cycle life by $30 \%-40 \%$ in a cycle fatigue and 3 - 3.5 times durability. Based on comprehensive research into the metallophysical surface-modified layer, new information is obtained about the nanoscale composition.
\end{abstract}

\section{Keywords}

Nanosized Structure, Shape Memory Effect, High-Speed Flame Spraying, Surface Plastic Deformation, Wear Resistance, Mechanical Fatigue

\section{Introduction}

Currently technologies using nanostructured alloys with a shape memory effect (SME) are rapidly developed as an independent field of modern materials relevance to fields of production, such as aircraft and automotive, 
medical, instruments, mechanical engineering, and space technology. At this stage, of greatest interest in the field of mechanical engineering there are comprehensive studies of the structure and properties of massive surface modified layers of nanostructured alloys with the shape memory effect, providing the functional and mechanical properties of the bulk material with memory, and bringing this to a level that is acceptable for practical use in machine parts and structural elements [1]-[5]. The widely known intermetallic-based TiNiCo has excellent functional properties [6] [7].

The aim of this work is to study the possibility of designing the structure of the surface layers of TiNiCo alloys using high-speed flame spraying to ensure functional and mechanical properties, and to provide cost-effective functional materials and components on this basis; also studied is the influence of the deposition and subsequent treatment consisting of surface plastic deformation at a temperature of $700^{\circ} \mathrm{C}-750^{\circ} \mathrm{C}$ and a surface plastic deformation at room temperature, and the properties of the modified surface layer of an alloy with shape memory effect.

\section{Research Methods}

We investigated the structural steel 1045 after a high-speed flame spraying with TiNiCo alloy using a universal installation for high-speed flame spraying (Figure 1). High-speed flame spraying of TiNiCo alloy powder was conducted on cylindrical specimens $(\varnothing 10 \times 50 \mathrm{~mm})$. As the combustible gas mixture, methane and oxygen were used, and argon gas was the carrier for the powder. High-speed flame spraying was carried out at an angle of inclination of the burner of $45^{\circ}-70^{\circ}$. The material used for the surface modification with powder was TiNiCo brand PN48.5T50K1.5. The particle size of the powder was $0.5-18 \mu \mathrm{m}$.

The study of large and small particles of PN48.5T50K1.5 powder showed that their structure same way: the shape of damaged perforated scales is most pronounced in larger particles (Figure 2). Thanks to such features, TiNiCo powders to tap have a bipolar structure, which is represented by very small intraparticle and large interparticle pores. Further analysis shows that the initial particle size of the powder has a significant effect on the properties of the formed layer. PN48.5T50K1.5 powder diffraction analysis determined that its structure consists of an austenitic phase ( $70 \%)$ and a martensitic phase ( $30 \%)$.

Before the high-speed flame spraying, the PN48.5T50K1.5 was dried in a vacuum oven for 3 - 6 hours at a temperature of $120^{\circ} \mathrm{C}-180^{\circ} \mathrm{C}$ on stainless steel trays with a thickness of layer up to $25 \mathrm{~mm}$. In order to improve the adhesive strength of the coating to the substrate, pre-shot blasting of the steel surface was carried out with subsequent etching with $15 \%$ nitric acid solution.

The structure and phase composition of the surface layer were examined by X-ray diffraction and optical microscopy. X-ray analysis was performed on a Shimadzu XRD-7000 Cu- $\mathrm{K}_{\alpha}$ radiation. Research and metallographic analysis of microstructures were carried out on an ultrahigh resolution scanning electron microscope JSM-7500F, a measuring microscope IMC-100, and optical microscopes MIM-8 and NU-2E (Carl Zeiss Jena). Identification of the microstructure of the steels and TiNiCo alloy was conducted in the respective etchants:

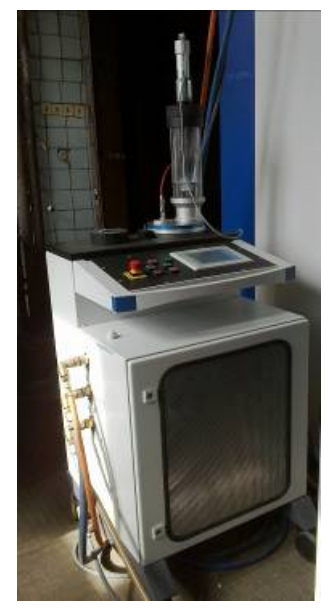

(a)

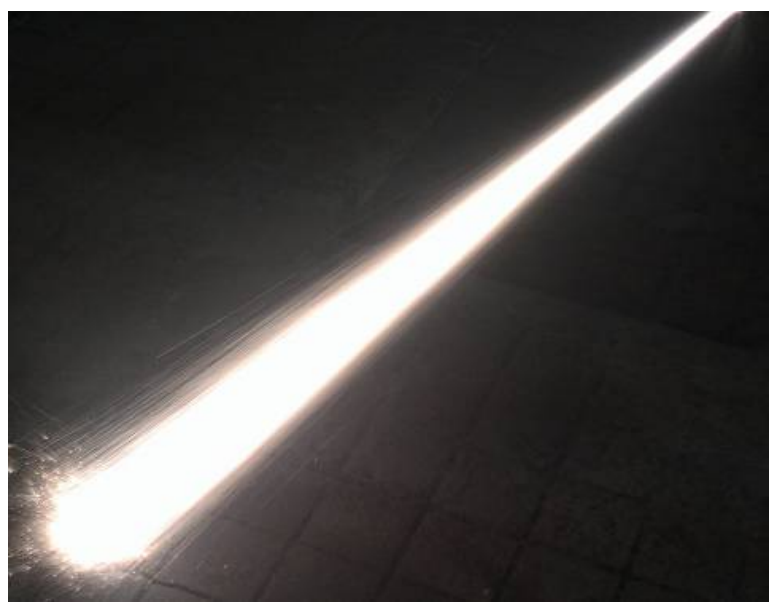

(b)

Figure 1. Hardware for high-speed flame spraying (a); The coating process (b). 

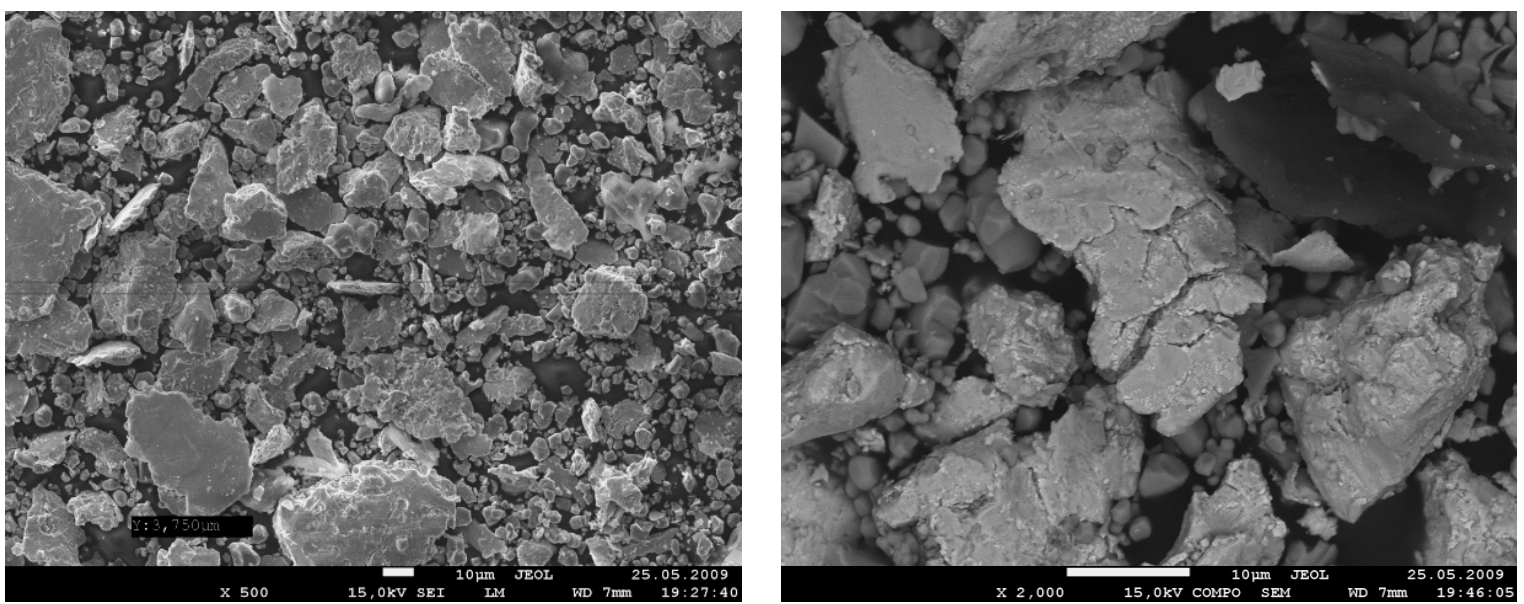

Figure 2. Morphology of the PN48.5T50K1.5 powder particles. Microhardness measurements were carried out on a PMT-3 with a $100 \mathrm{~g}$ load on the indenter.

$-\mathrm{HNO}_{3}(0.5 \mathrm{ml}), \mathrm{HCl}(1 \mathrm{ml})$, glycerol $(1-2 \mathrm{ml})$;

$-\mathrm{CuSO}_{4}(1 \mathrm{~g}), \mathrm{HCl}(5 \mathrm{ml}), \mathrm{H}_{2} \mathrm{O}(5 \mathrm{ml})$;

$-\mathrm{NO}_{3}(10-20 \mathrm{ml}), \mathrm{HF}(10-20 \mathrm{ml})$, glycerol $(20-60 \mathrm{ml})$.

\section{Technology for Producing Nanostructured Coatings with Shape Memory Effect (SME)}

Figure 3 shows the upgraded cogeneration unit used to produce nanostructured coatings with a shape memory effect (SME).

The installation consists of the following structural elements: the control unit 1; magnetrons 2 for magnetron sputtering of metals; vacuum chamber 3; source 4 for ion implantation of metals; supply 5 for the magnetron 2; V source 6 for ion implantation; gas-flame burner 7 for high-speed flame spraying, installed at an angle of $45^{\circ}$ to the surface of the workpiece; power supply 8 for high-speed flame spraying; press 9 ; lower traverse 10 of the press; upper yoke of the press 11; device 12 for cooling the parts made in two containers filled with liquid nitrogen; a powder dispenser 13; pyrometer 14; workpiece 15; working gas cylinders 16; frame 17; a vacuum pump 18; process module 19 for ion cleaning of the workpiece 15 surfaces; step-down transformer 20; clamping device 21; line 22.

The combined process of the preparation of nanostructured alloys with shape memory effect PN48.5T50K1.5 was as follows: workpiece 15 is mounted on the lower cross member 10 of the press 9 , with a clamping device 21 , and the vacuum pump 18 is pumped vacuum chamber of $36.5 \times 10^{-3}-6.8 \times 10^{-3} \mathrm{~Pa}$. Next the vacuum chamber is filled with argon to a pressure of $0.07-0.6 \mathrm{~Pa}$, and the process module 19 is used to produce ion cleaning of the hardenable details 15 . With power supply 8 and the control unit 1 together with flame burner 7 , high-speed flame spraying is conducted with simultaneous supply powder shape memory line 22 transport from the powder dispenser 13. Also produced are magnetrons including two magnetron sputtering of metals with shape memory effect. A temperature measurement part 15 in the processing zone is made pyrometer 14. Press 9 the lower 10 and upper 11 traverse is used for surface plastic deformation of the coating obtained with shape memory effect immediately after high-speed flame spraying, with the magnetron and ion implantation of metals. The workpiece 15 is fixed on the movable bottom 10 traverse of press 9, starts the vertical movement of the lower cross member 10 upward until it contacts the coated workpiece with the obtained top crossbeam 11 to achieve a predetermined pressure on the surface of the coated parts prior to its deformation. Spray coating is done with flame burner 7 which is at an angle of $45^{\circ}$ to the surface of the workpiece 15, as magnetrons 2 and source ion implantation of metals. On the lower cross member 10 of the press 9 device 12 is installed for cooling the shape memory effect coating in the case of a negative temperature range of martensitic transformation at surface plastic deformation. Plastic deformation of the surfactants immediately after the high-speed flame spraying, magnetron sputtering, and ion implantation is carried out in three stages; the first stage is carried out in the temperature range $300^{\circ} \mathrm{C}-400^{\circ} \mathrm{C}$, the second in the temperature interval $400^{\circ} \mathrm{C}-500^{\circ} \mathrm{C}$, and the third in the temperature range of martensitic transformation $\left(\mathrm{M}_{\mathrm{s}}-\mathrm{M}_{\mathrm{f}}\right)$, by means of heating element 20 connected to the clamping device 21 of the work piece 15 . 


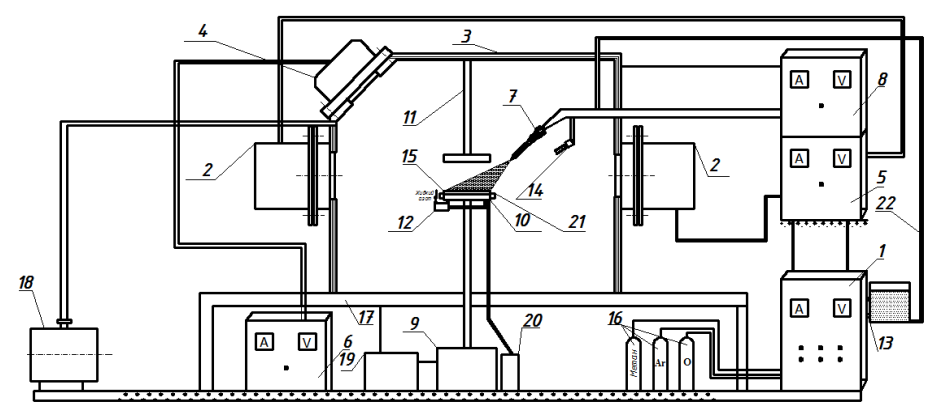

Figure 3. Upgraded cogeneration unit to produce nanostructured coatings with shape memory effect.

\section{Results and Discussion}

In developing the technology for surface modification of steel 1045 with TiNiCo in connection with the thermal characteristics of the alloying powders (the difference in thermal expansion coefficients of titanium and steel (about 8.3 and 16)), experiments on high-speed flame spraying of TiNiCo directly on the steel led to unsatisfactory results associated with visual defects in the coatings obtained (poor adhesion strength of the coating to the substrate, cracking, peeling). For a binder of the intermediate layer between the steel and nickel, TiNiCo powders were used, having unlimited solubility of iron and having an affinity for most second-phase particles, from which it is easy to form the coating.

The analysis parameters for the basic high-speed flame spraying include: combustible fuel gas (methane, oxygen) flow of powder and carrier gas (argon), spraying distance, spray angle, moving speed and feeding of the burner flame, and the rotation speed of the covered part. Studies have shown that the formation of the surface layer of shape-memory-based TiNiCo yields the best quality coverage at combustible gases flow rates of methane 70 - $75 \mathrm{l} / \mathrm{min}$, and oxygen 150 - $160 \mathrm{l} / \mathrm{min}$. (Figure 4), which increases the strength of adhesion of the coating to the substrate as well as the cohesive strength, and reduces the levels of residual stress and porosity in the TiNiCo alloy.

Macro analysis of the surface layers of the TiNiCo alloy, obtained using proven technology, showed that the structure of the coating is sufficiently dense, with a minimum content and the size of pores in the shape memory TiNiCo coating. The interface between the coating and the substrate was without any visible cracks. Metallographic examination of the coatings obtained via high-speed flame spraying showed the following patterns. After passing the powder particles through the gas stream, they were heated and when they struck the substrate they solidified in the form of deformed discs with a diameter and thickness 5 - $25 \mu \mathrm{m}$ and $0.5-1 \mu \mathrm{m}$.

At room temperature, the main structural components of the TiNiCo surface layer are austenitic B2 phase with a cubic lattice, the martensitic phase B19' with a monoclinic lattice, $\mathrm{NiTi}_{2}$ phase with a cubic lattice, $\mathrm{Ni}_{3} \mathrm{Ti}^{\mathrm{B}}$ phase with a hexagonal lattice, $\mathrm{Ni}_{4} \mathrm{Ti}_{3}$ phase with a rhombohedral lattice, and there is a small amount (less than 2\%) of titanium oxide ( $\mathrm{TiO}$ ) (Figure 5).

The $\mathrm{Ni}_{3} \mathrm{Ti}$ and $\mathrm{NiTi}_{2}$ phases are mainly allocated in the process of crystallization and are located along the grain boundaries. To address them requires homogenizing annealing in an inert atmosphere (vacuum) at a temperature of $800^{\circ} \mathrm{C}-1000^{\circ} \mathrm{C}$ for $1-2 \mathrm{~h}$. It is known that the presence in the structure of the particle phases $\mathrm{Ni}_{3} \mathrm{Ti}$ and $\mathrm{NiTi}_{2}$ (size $15-40 \mathrm{~nm}$ ) leads to a decrease in the temperature range of martensitic transformation $\mathrm{B} 2 \rightarrow$ B19'.

In [8] it is shown that the aging nickel alloys in the early stages allocated metastable $\mathrm{Ti}_{3} \mathrm{Ni}_{4}$ phase with a rhombohedral lattice (with parameters $\mathrm{a}=0.66 \mathrm{~nm}, \alpha=113.7^{\circ}$ ). $\mathrm{Ti}_{3} \mathrm{Ni}_{4}$ particles have an orientation relationship with the austenite B2 structure and create $<111>$ in the direction perpendicular to the plane of the particle, with a tensile stress: [111] B2 $\left\|[111] \mathrm{Ti}_{3} \mathrm{Ni}_{4},(321) \mathrm{B} 2\right\|(101) \mathrm{Ti}_{3} \mathrm{Ni}_{4}$. These tensile stresses coincide with the rhombohedral distortion, which corresponds to the elongation of the body diagonal of the crystal lattice of the B2 phase at $\mathrm{B} 2 \rightarrow \mathrm{R}$ transformation. After thermal cycling, B2 $\rightarrow \mathrm{R}$ transition is highly reversible [9]. From [10] we know that if the $\mathrm{Ti}_{3} \mathrm{Ni}_{4}$ particle size ranges from $100 \mathrm{~nm}$ to 1 or 2 microns, martensitic transformations are carried out on the $\mathrm{B} 2 \rightarrow \mathrm{R} \rightarrow \mathrm{B} 19 '$. With the depletion of nickel matrix and the loss of coherence due to the B2 matrix, the surface of large particles of $\mathrm{Ti}_{3} \mathrm{Ni}_{4}$ is the birthplace of the martensite B19' [10]. Production of $\mathrm{Ti}_{3} \mathrm{Ni}_{4} \mathrm{Particles}$ can occur during annealing with attached elastic stresses [11]. 


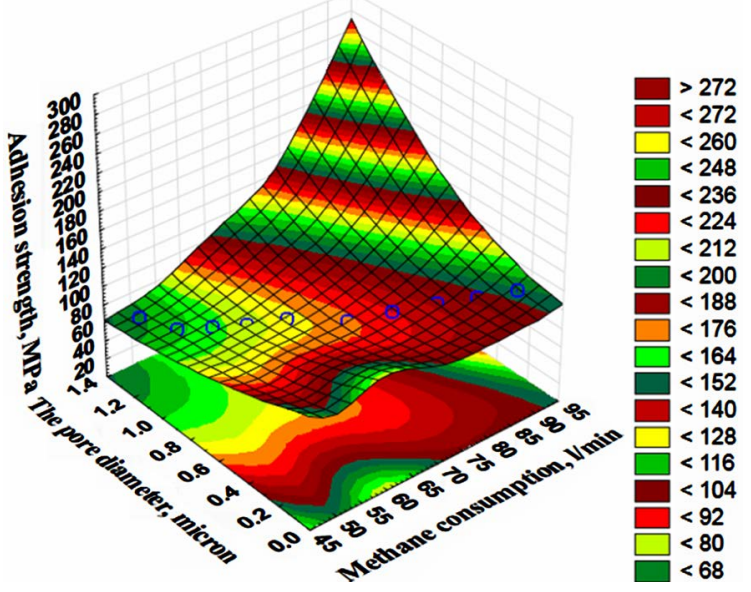

(a)

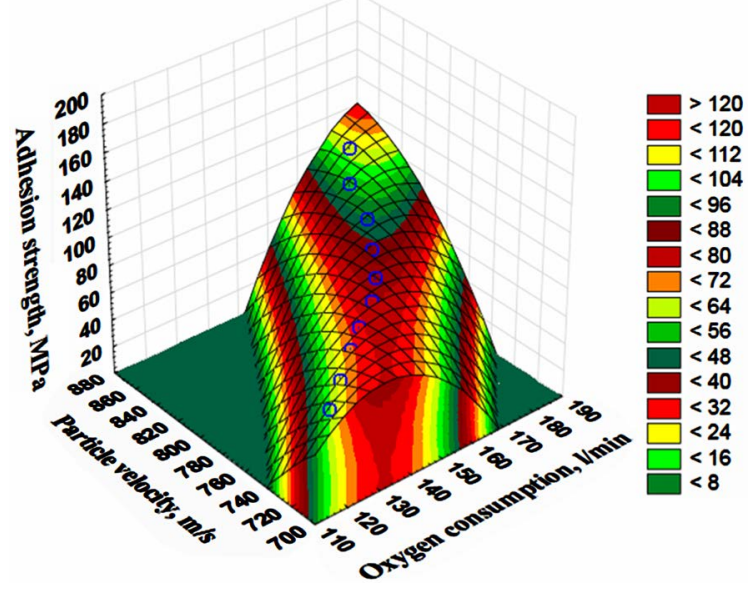

(b)

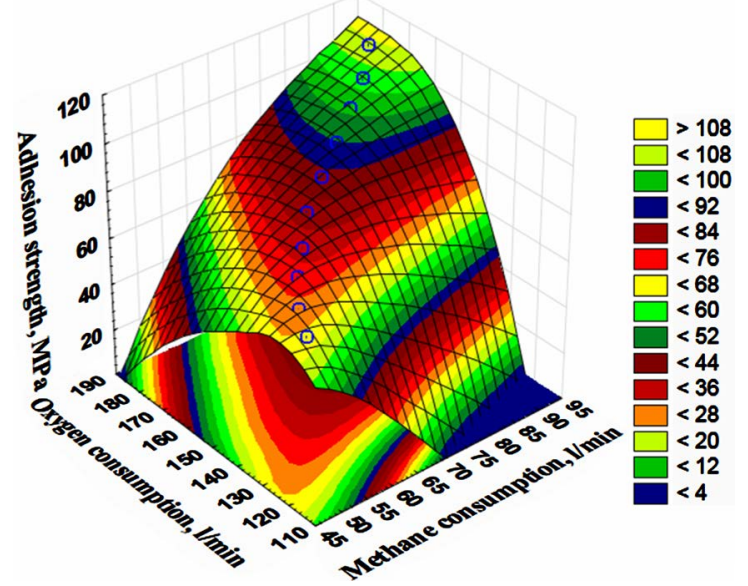

(c)

Figure 4. Influence of the composition of combustible gases on the adhesive strength of the coating with the shape memory effect TiNiCo (a)-(c).

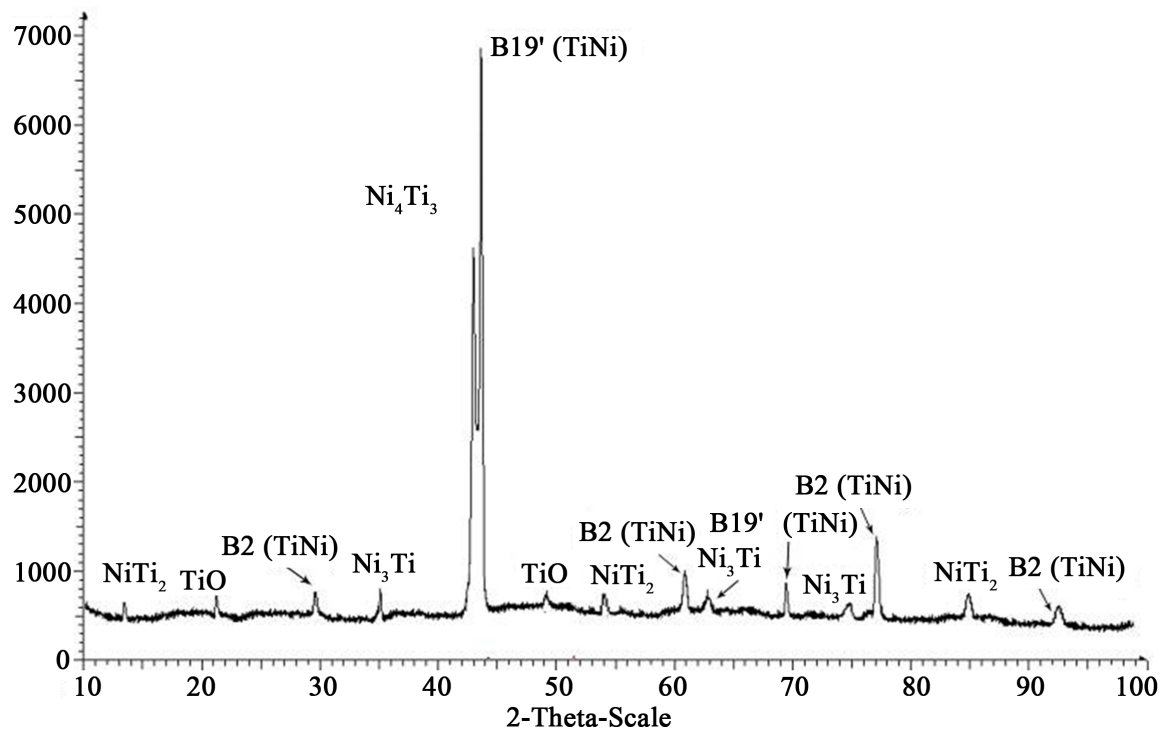

Figure 5. X-ray diffraction analysis of the TiNiCo alloy after high-speed flame spraying. 
As shown by metallographic analysis, the structure formed as a result of high-speed flame spraying with layers of TiNiCo alloys is extremely weak etched conventional reagents due to the strong grain refinement as a result of the high-speed collision of particles with the substrate and the high speed of cooling. Further studies have found that provides specific structural effects.

The resulting coating has TiNiCo nanoscale structures with a grain size of $30-190 \mathrm{~nm}$ (Figure 6). In many ways, the formation of such a coating is associated with features of the high-speed flame spraying (high-speed collision of particles with the substrate, high speed of cooling and rapid quenching of the alloy). Figure 7 shows the quantitative distribution of the grain size and the percentage of the TiNiCo coating, as a percentage of the pore size.

For all the samples, increased microhardness of the sprayed layer of TiNiCo was observed relative to the base metal. The microhardness distribution in the thickness of TiNiCo after high-speed flame spraying on steel 1045 is shown in Figure 8. The microhardness of the TiNiCo layer varies in the range $\mathrm{H}_{\mu}=9.2-11.6 \mathrm{GPa}$. This increase in the microhardness is due to the fact that after the high velocity collisions between particles and the substrate, the high speed of the rapid cooling and quenching of the alloy formed a high-strength metastable structure.

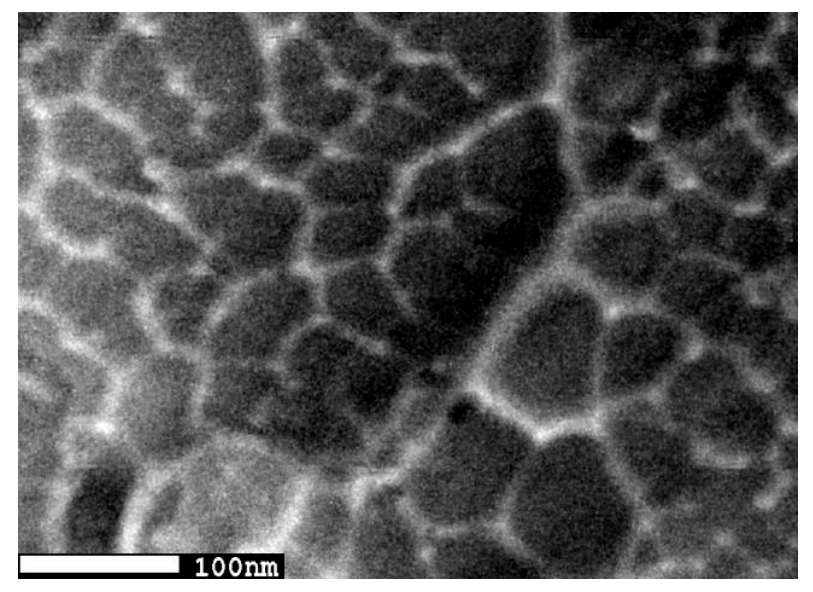

(a)

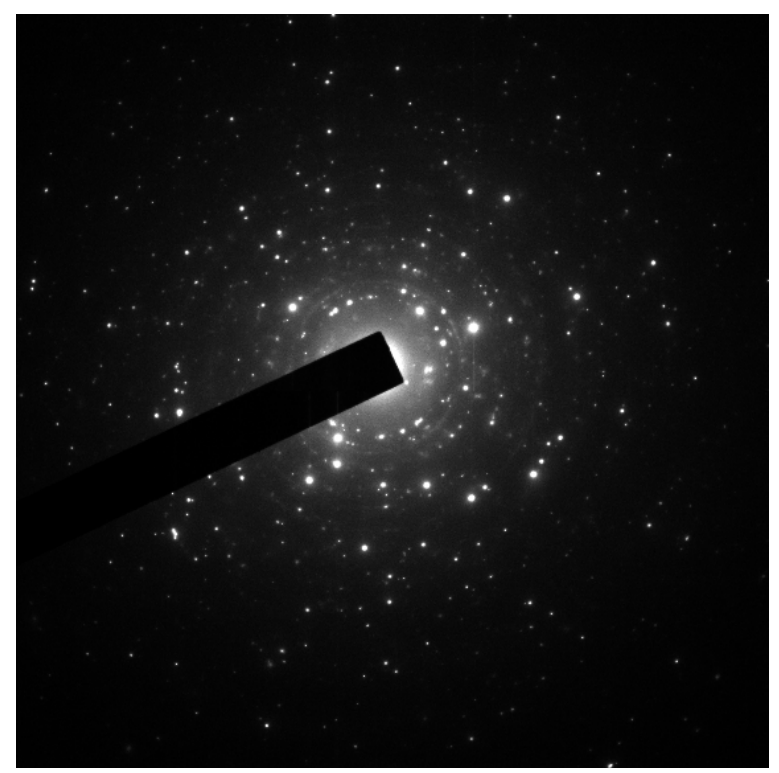

(c)

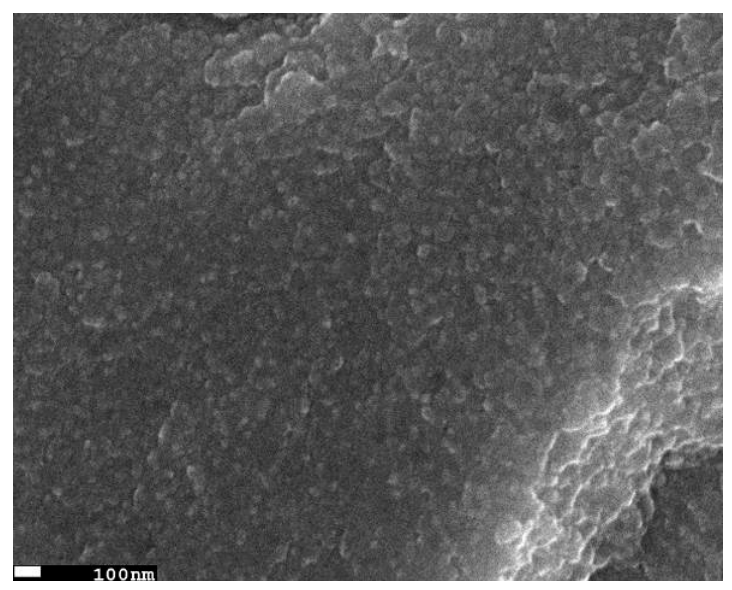

(b)

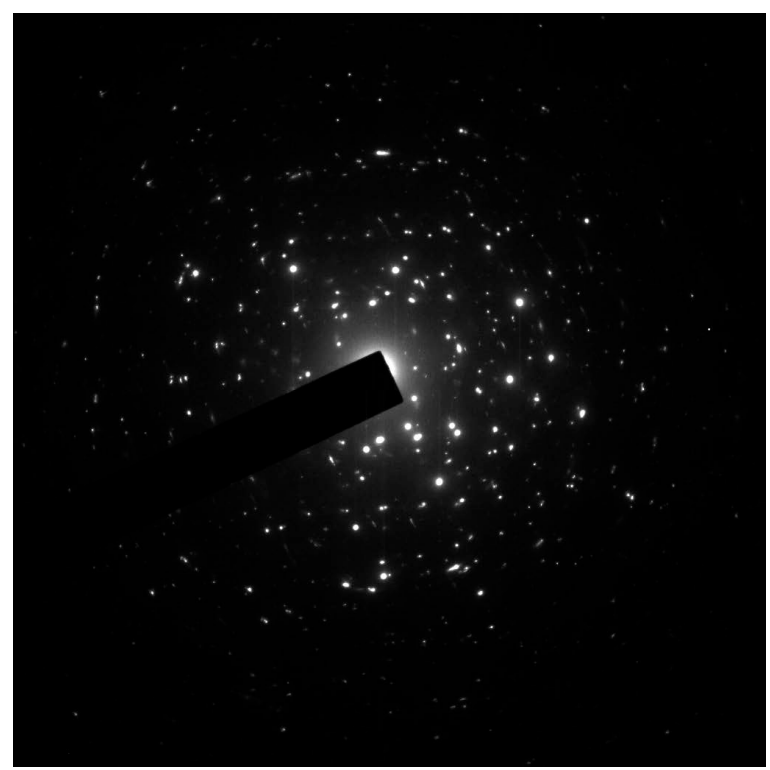

(d)

Figure 6. TiNiCo nanoscale coating obtained via high flame spraying, $\times 150,000$ (a) (b); Electron diffraction austenitic and martensitic B2 B19' phase $\mathrm{Ti}_{2} \mathrm{Ni}, \mathrm{Ni}_{3} \mathrm{Ti}_{2} \mathrm{Ni}_{4} \mathrm{Ti}_{3}$ with small titanium oxide inclusions (c) (d). 


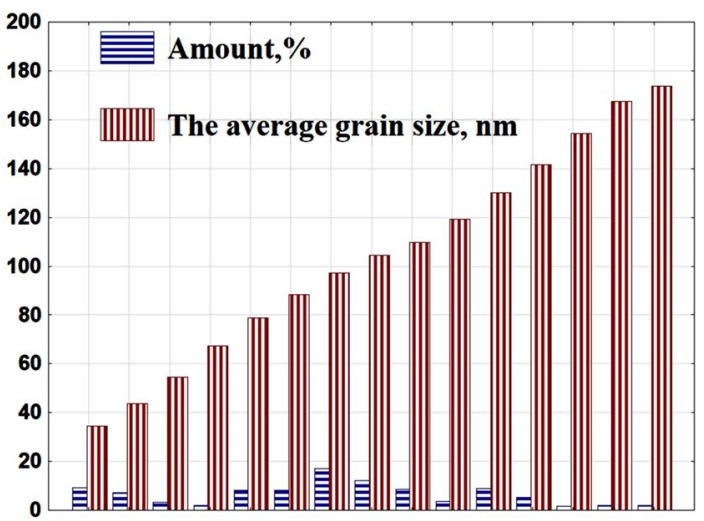

(a)

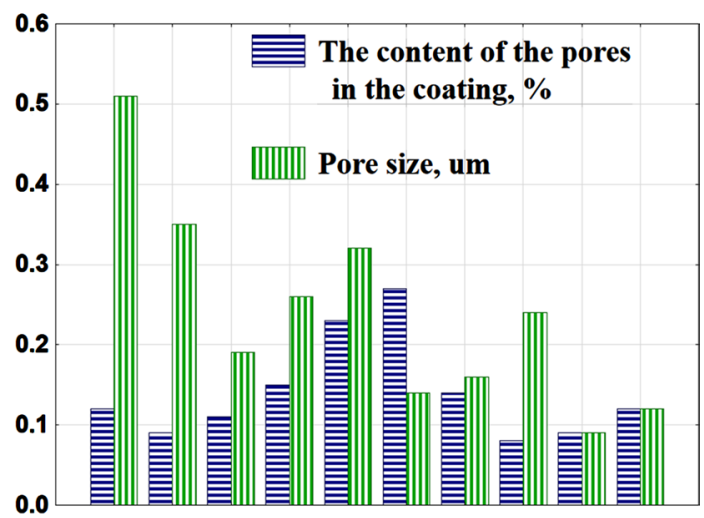

(b)

Figure 7. Quantitative grain size distribution and their percentages in the TiNiCo coating (a); The percentage of pore sizes with the size of their coverage in the TiNiCo (b).

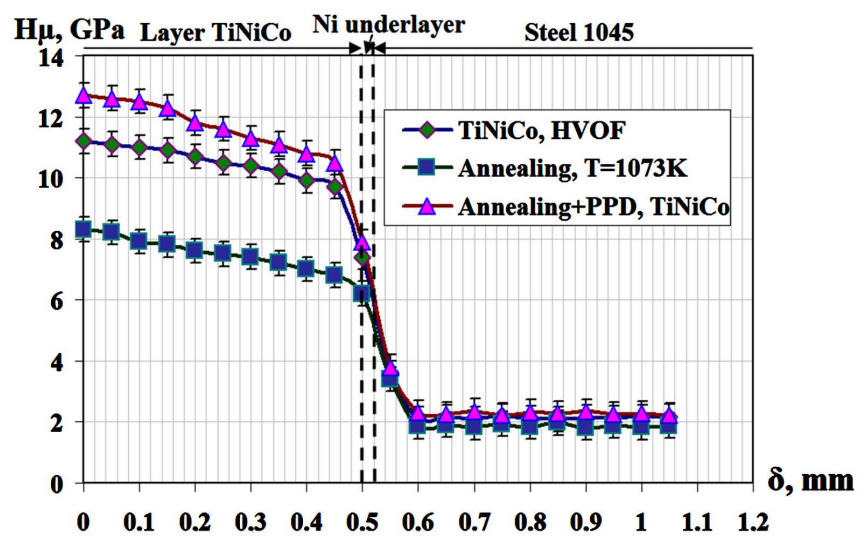

Figure 8. Distribution of microhardness of the Ni-TiNiCo alloy, obtained after high-speed flame spraying of steel $1045, \delta_{\text {TiNiCo }}=0.5 \mathrm{~mm}$.

\section{Thermal and Thermomechanical Processing Layers of Alloys with Shape Memory Effect TiNiCo}

High-speed flame spraying of shape memory effect coatings is a multi-step process, where each step of the process parameters improves the functional and mechanical properties. One of these phases is the thermal operation. High-speed flame spraying of alloys with shape memory effect based on TiNiCo leads to a high density of crystal defects and internal strains (stresses of the first kind or residual), the magnitude and nature of which are determined by the nature of the spray material and deposition conditions. The internal stress hindering the mobility of twin boundaries can lead to a reduction of the functional mechanical properties of the resulting layer, as well as cracking or peeling of the coating from the substrate. In accordance with the mechanism of relaxation of internal residual stresses during annealing, partial or complete relaxation is by means of processes occurring during homogenization or recrystallization annealing. In this, annealing is used as a means of improving the characteristics of the shape memory, since the relaxation of internal stresses of martensite twins may be moveable within the available sub-boundaries [12]. Thermal treatment (TT) is an intermediate step in this paper, which results in the stabilization of the structure of the TiNiCo coating, improving the memory properties while reducing the residual stresses after deposition of TiNiCo. In this work, the annealing temperature of the TiNiCo alloy was $800^{\circ} \mathrm{C}(1073 \mathrm{~K})$, and the annealing was carried out in an inert atmosphere (argon) for $1 \mathrm{~h}$ followed by cooling with the oven.

The heat treatment has a significant impact on the structure of the coating and the steel structure as a result of the structural changes that occur. X-ray and metallographic analysis of the surface alloy layers of TiNiCo after annealing at $1073 \mathrm{~K}$ shows the presence of B2-austenitic phase, martensite phase $\mathrm{B} 19$ ', $\mathrm{Ni}_{4} \mathrm{Ti}_{3}$ phase, and TiO 
(less than $1 \%$ ).

After annealing, the grain size is increased by 1.5 - 2 times, and the grains of TiNiCo alloy with shape memory effect have sizes of the order of $250-350 \mathrm{~nm}$ (Figure 9). This has a significant impact on the microhardness of the coatings, which is "sensitive" to the structural changes, such that there is some "softening" of the alloy and a decrease in the microhardness of the TiNiCo covering (Figure 8). Thus, annealing has a significant impact on the structure, microhardness, composition, and elimination of chemical heterogeneity of the surface layers of TiNiCo, the result of which is an improvement of the properties of alloys with shape memory effect.

Surface plastic deformation is one of the types of thermomechanical processing of materials. Thermomechanical treatment is a combined cycle of heat treatment and plastic deformation, providing a way to manage the functional and mechanical properties of TiNiCo alloys with shape memory effect. Surface plastic deformation leads to hardening of the layer of shape memory TiNiCo, decreasing the surface roughness, and leading to pore elimination. Surface plastic deformation is the final stage of thermomechanical cycle of the items of alloys with shape memory effect, enhancing their functional properties.

To create a level of reactive stresses and reversible deformation for shape recovery of layers of alloys with shape memory effect, surface plastic deformation of the TiNiCo layers is necessary. The coating structure obtained after high-speed flame spraying, thermal treatment (annealing at $800^{\circ} \mathrm{C}$ ) and subsequent plastic deformation of the surface is represented in Figure 10. Immediately after high-speed flame spraying is carried out, surface plastic deformation of the TiNiCo layer with the shape memory effect is carried out (Figure 3). After this operation, heat treatment is conducted on the surface plastic deformation layer of shape memory TiNiCo at room temperature. As a result of plastic deformation of the surface, the grain size decreases and uniform distribution in the depth of the layer. After the surface plastic deformation and thermal cycling, a homogeneous nanoscale layer structure of TiNiCo is obtained with a grain size of 80 - $200 \mathrm{~nm}$ grains in TiNiCo layer elongated (Figure 10(a) and Figure 10(b)).

We carried out tests on the high-cycle bending fatigue by rotating the samples from the steel 1045 surfacemodified with shape memory effect TiNiCo alloy, and showed a significant increase in longevity (Figure 11(a)). The highest value of the amplitude of the alternating voltage at which the samples are not destroyed by the base number of cycles (endurance limit, $\sigma_{-1}$ ) for uncoated steel 1045 was $275 \mathrm{MPa}$, and after surface modification with shape memory effect TiNiCo-420 MPa, an increase of $\approx 34.5 \%$.

Figure 11(b) shows the results of the wear test on samples of steel 1045. Figure 11(c) shows the results of the wear test on samples of steel 1045 with a nanostructured surface layer of TiNiCo with a thickness of $0.5 \mathrm{~mm}$ obtained via a high-speed flame spraying. The tests were conducted under conditions of dry friction at various disk sliding speeds. In the process of loading, the temperature was measured at the point of contact. The experimental data were carried out using the application package Statistica v10.0 environment SPSS. Analysis of the relationship shows (Figure 11(c)) that at high test speeds it has become virtually non-existent during the break-in period, and at low speeds it is weakly expressed. The wear resistance of the surface modified layer of TiNiCo is increased by 3 - 3.5 times compared with steel 1045 .

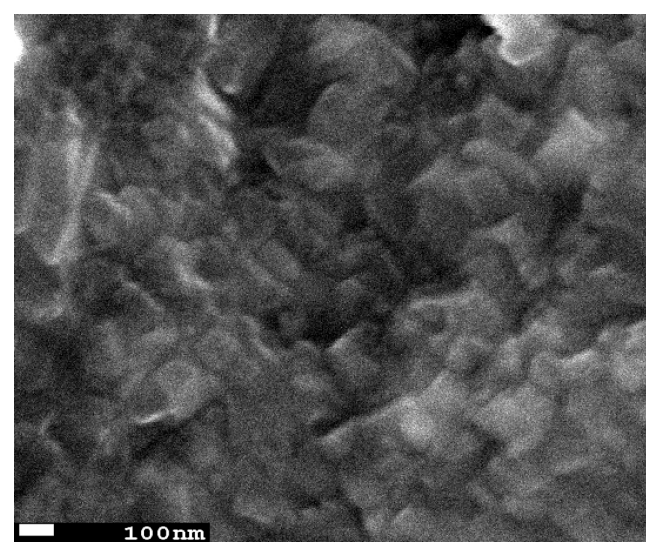

(a)

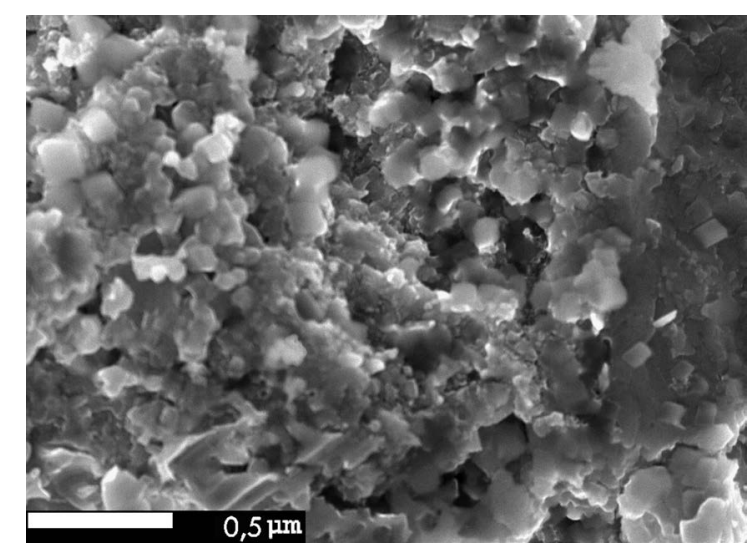

(b)

Figure 9. Microstructure of TiNiCo covering with shape memory effect after heat treatment (annealing at $\mathrm{T}=$ $1073 \mathrm{~K}) \times 50,000(\mathrm{a}) ; \times 35,000(\mathrm{~b})$. 


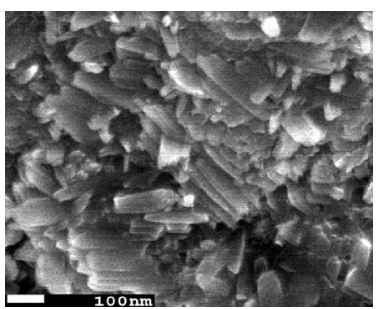

(a)

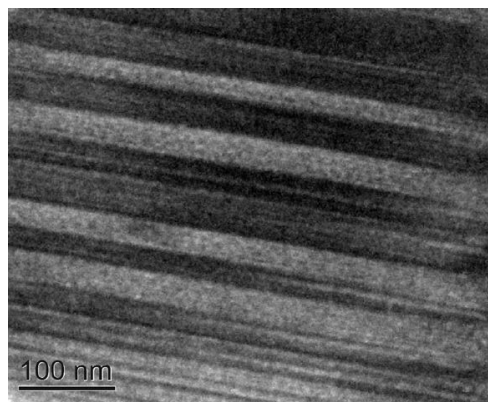

(c)

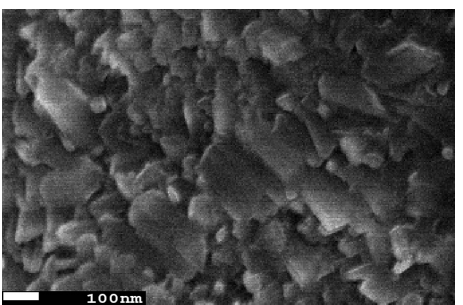

(b)

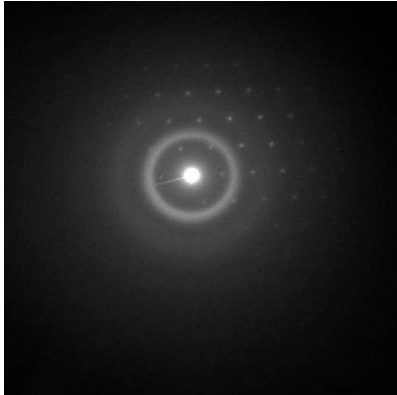

(d)

Figure 10. The microstructure of the alloy layer with TiNiCo after thermomechanical treatment (a)-(c). $\times 45$ 000 (a); $\times 50,000$ (b); $\times 80,000$ (c); Electron diffraction of TiNiCo alloy after thermomechanical treatment (d).

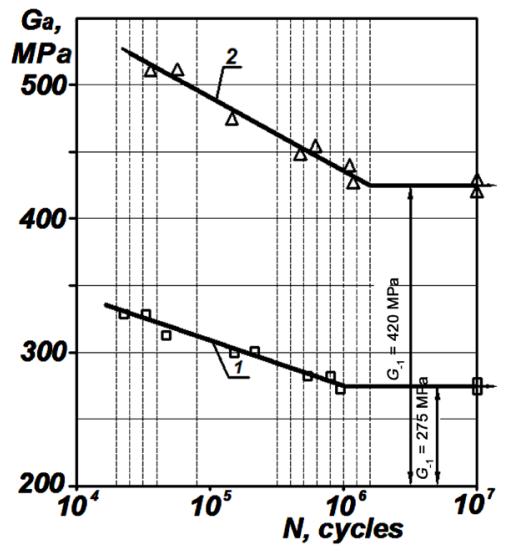

(a)

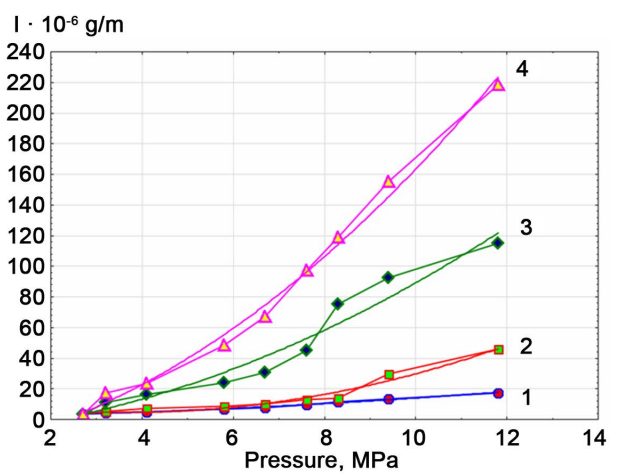

(b)

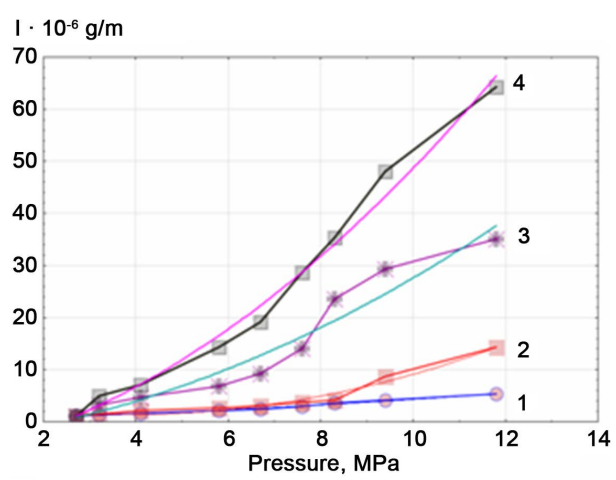

(c)

Figure 11. Cycle fatigue curves: uncoated (1), after the surface modification with shape memory effect TiNiCo (2) (a); Uncoated, steel 1045: sliding speed drive $0.5 \mathrm{~m} / \mathrm{s}$ (1); $1 \mathrm{~m} / \mathrm{s}$ (2); $1.5 \mathrm{~m} / \mathrm{s}$ (3); $2 \mathrm{~m} / \mathrm{s}$ (4) (b); Dependence of the wear rate I on the pressure $\mathrm{F}$, after the surface modification with shape memory effect TiNiCo: sliding speed drive $0.5 \mathrm{~m} / \mathrm{s}(1) ; 1 \mathrm{~m} / \mathrm{s}(2) ; 1.5 \mathrm{~m} / \mathrm{s}$ (3); $2 \mathrm{~m} / \mathrm{s}$ (4) (c). 


\section{Conclusions}

On the basis of analysis of experimental data, the optimal modes of the process of surface modification with TiNiCo of steel 1045 using high-speed flame spraying were obtained. The resulting coatings have the austenitic structure of the B2 phase with a cubic lattice, the martensitic phase B19' with a monoclinic lattice, $\mathrm{Ti}_{2} \mathrm{Ni}$ phase with a cubic lattice, $\mathrm{Ni}_{3} \mathrm{Ti}$ phase with a hexagonal lattice, $\mathrm{Ni}_{4} \mathrm{Ti}_{3}$ phase with a rhombohedral lattice, and TiO.

Due to the intermediate sublayer of nickel and the pre-processing steps, a solid grip on the steel-TiNiCo border is provided.

A universal system for the preparation of nanostructured coatings with shape memory effect is presented.

We established the control processing parameters that control the structural state of the material at the stage of the surface-modified layer and the subsequent combined treatment, which makes it possible to influence the properties of the shape memory effect of the surface layer of TiNiCo.

As a result of the heat treatment, there is a stabilization of the TiNiCo coating structure, improving the memory properties while reducing residual stresses after deposition of the TiNiCo alloy.

As a result, surface plastic deformation leads to the elimination of pores in the coating, increasing the density of coverage ( $10 \%-12 \%)$, increasing the strength of adhesion of the coating to the substrate $(35 \%-40 \%)$, increasing the microhardness, and improving the functional and mechanical properties and deformation-force parameters of the alloy layers with shape memory effect TiNiCo.

It was established experimentally that after a high-speed flame spraying powder treatment the mechanically activated shape memory TiNiCo's cyclic durability under high-cycle fatigue is increased by $\sim 34.5 \%$. The wear resistance of steel after deposition and annealing of the TiNiCo layer increased 3 - 3.5 times and after their treatment in the thermomechanical cycle increased 3.5 times.

Thus, set high cycle fatigue resistance, increased wear layers of alloys with shape memory effect based on TiNiCo steels 1045 in combination with giving them new functional properties.

\section{Funding}

This work was supported by grant of the President of the Russian Federation and the Ministry of Education and Science of the Russian Federation within the framework of the project in 2416 (2014 g.).

\section{References}

[1] Blednova, Zh.M. and Rusinov, P.O. (2010) Formation of Nanostructured Surface Layers by Plasma Spraying the Mechanoactivated Powders of Alloys with Shape Memory Effect. Nanotechnologies in Russia, 5, 352-363. http://dx.doi.org/10.1134/S1995078010050101

[2] Blednova, Zh.M. and Rusinov, P.O. (2013) Formation of Nanostructured Surface Layers from Materials with Shape Memory Effect TiNiCu in Conditions. Materials Science Forum, 738-739, 512-517. http://dx.doi.org/10.4028/www.scientific.net/MSF.738-739.512

[3] Blednova, Z.M., Rusinov, P.O. and Stepanenko, M.A. (2013) Superficial Modifying by SME Materials in Engineering Appendices. Materials Science Forum, 738-739, 595-600. http://dx.doi.org/10.4028/www.scientific.net/MSF.738-739.595

[4] Blednova, Zh.M. and Rusinov, P.O. (2014) Mechanical and Tribological Properties of the Composition Steel-Nanostructured Surface Layer of a Material with Shape Memory Effect Based TiNiCu. Applied Mechanics and Materials, 592-594, 1325-1330. http://dx.doi.org/10.4028/www.scientific.net/AMM.592-594.1325

[5] Blednova, Z.M., Rusinov, P.O. and Stepanenko, M.A. (2014) Influence of Superficial Modification of Steels by Materials with Effect of Memory of the Form on Wear-Fatigue Characteristics at Frictional-Cyclic Loading. Advanced Materials Research, 915-916, 509-514. http://dx.doi.org/10.4028/www.scientific.net/AMR.915-916.509

[6] Lekston, Z. and Drugacz, J. (2007) Structure and Properties of NiTi and TiNiCo Shape Memory Wires for Maxillofacial Surgery. $12^{\text {th }}$ International Scientific Conference Achievements in Mechanical and Materials Engineering, 593596.

[7] Lekston, Z. and Lagiewka, E. (2007) X-Ray Diffraction Studies of NiTi Shape Memory Alloys. Archives of Materials Science and Engineering, 28, 665-672.

[8] Khachin, V.N. (1992) Titanium Nikelid. Structure and Properties. Nauka, Moscow.

[9] Tobushi, H., Kimura, K., Sawada, T., Hattori, T. and Lin, P. (1994) Recovery Stress Associated with R Phase Transformation in TiNi Shape Memory Alloy. JSME International Journal, Series A, 37, 138-142. 
[10] Zel'dovich, V.I., Khomskaya, I.V., Frolova, N.Y., et al. (2001) On the Origin of R Martensite in Titanium Nickelide. FMM, 92, 71-76.

[11] Khalil-Allafi, J., Dlouhy, A. and Eggeler, G. (2002) $\mathrm{Ni}_{4} \mathrm{Ti}_{3}$-Precipitation during Aging of NiTi Shape Memory Alloys and Its Influence on Martensite Phase Transformation. Acta Materialia, 50, 4255-4274.

http://dx.doi.org/10.1016/S1359-6454(02)00257-4

[12] Karabasova, Y.S., Ed. (2002) New Materials. MISIS, 736s. 
Scientific Research Publishing (SCIRP) is one of the largest Open Access journal publishers. It is currently publishing more than 200 open access, online, peer-reviewed journals covering a wide range of academic disciplines. SCIRP serves the worldwide academic communities and contributes to the progress and application of science with its publication.

Other selected journals from SCIRP are listed as below. Submit your manuscript to us via either submit@scirp.org or Online Submission Portal.
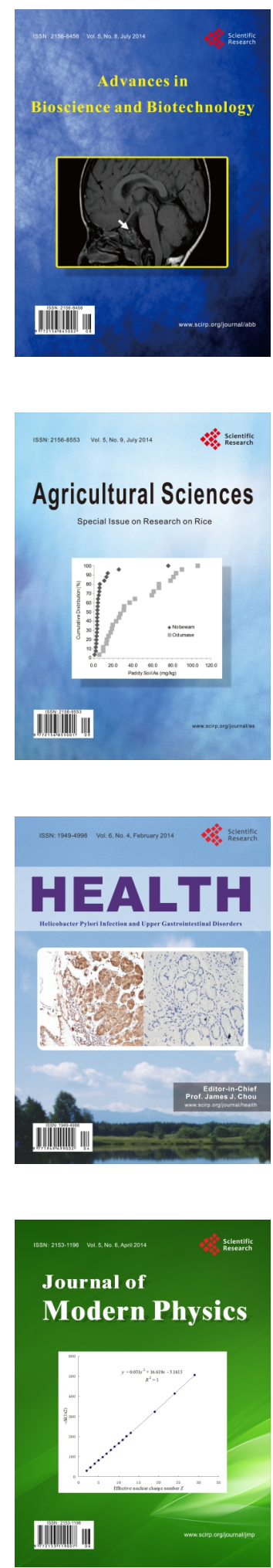
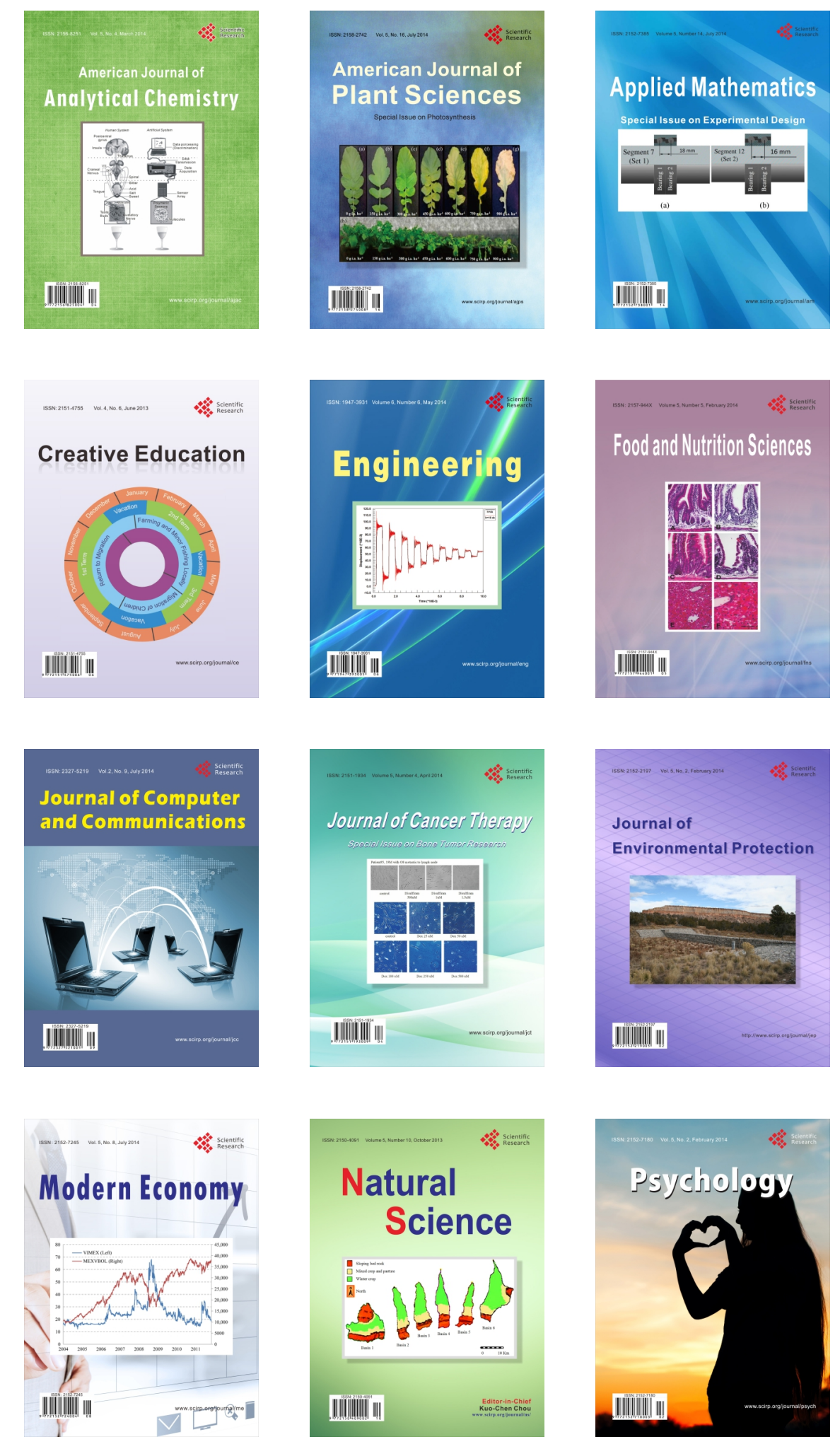